\title{
Efeitos de Níveis e Períodos de Adaptação à Lasalocida Sódica sobre os Parâmetros de Fermentação Ruminal
}

\author{
Fabiano de Rezende Amaro1, Carlos de Souza Lucci², Kléber da Cunha Peixoto Júnior', \\ Ari Luiz de Castro ${ }^{3}$
}

\begin{abstract}
RESUMO - Foram comparados os efeitos de períodos de adaptação e níveis de lasalocida sódica sobre a fermentação ruminal em quatro vacas mestiças: Holandês-zebu. O delineamento experimental empregado foi o quadrado latino, composto de quatro períodos de seis semanas cada, colhendo-se dados, isoladamente da primeira, segunda, terceira e quarta semanas, para estudo de tempos de adaptação, destinando-se à quinta e sexta semanas, para eliminação de efeitos residuais. Os tratamentos foram: controle e suplementação, com 50,100 e 200mg de lasalocida/indivíduo/dia, determinando-se, no conteúdo do rúmen, a concentração dos ácidos graxos voláteis acético, propiônico e butírico, pH, amônia, taxa de passagem e volume de líquidos. Não foram registrados efeitos dos diferentes níveis da lasalocida sódica ou de períodos de adaptação; com base nestes resultados, não é possível indicar a aplicação do ionóforo para bovinos, na expectativa de provocar alterações na fermentação ruminal em bovinos.
\end{abstract}

Palavras-chave: bovinos, fermentação ruminal, ionóforos, lasalocida sódica

\section{Effects of Levels and Adaptation Periods to Sodium Lasalocid on the Rumen Fermentation Parameters}

\begin{abstract}
Effects of adaptation periods to sodium lasalocid and its ionophorum levels were evaluated on ruminal fermentation, using four Holstein-Zebu cross-breed cows. Latin square was the experimental design used, with four periods of six weeks, in which isolated data from the first, second, third and fourth weeks were used to evaluate periods of adaptation, and the last two destined to eliminate residual effects. Treatments were no supplementation and supplementation with 50, 100 and 200 mg of sodium lasalocid/ head/day, and rumen vollaty fatty acid acetic, propionic and butiric, $\mathrm{pH}$, ammonia, liquid turnover and flow rate were measured every week. There were no differences in results for levels or periods of adaptation, and considering these results, it is not recommended the use of sodium lasalocid to modify ruminal fermentation parameters in cattle.
\end{abstract}

Key Words: cattle, ionophores, ruminal fermentation, sodium lasalocid

\section{Introdução}

O ionóforo lasalocida, quando consumido pelos ruminantes, tem apresentado efeitos bastante variáveis sobre certos parâmetros de fermentação ruminal (Spears \& Harvey, 1987). A lasalocida provoca alteração na flora microbiana do conteúdo do rúmen, incrementando as bactérias gram-negativas e provocando diminuição acentuada nas gram-positivas, sendo esta modificação responsável pelas alterações na fermentação ruminal (Chen \& Wollin, 1979; Block \& Burchard, 1998).

Autores como Johnson et al. (1988), ReffetStabel et al. (1989) e Weiss \& Amiet (1990) sugeriram a hipótese da variação nas respostas obtidas na administração dos ionóforos ocorrer devido à adapta- ção das bactérias ruminais ao seu emprego. De acordo com Katz et al (1986), a lasalocida apresentou, in vitro, tendência em diminuir a produção de acetato e aumentar a de propionato, quando o inóculo foi obtido de animais não adaptados, não sendo observado efeito quando o inóculo era proveniente de animais adaptados. Spears \& Harvey (1987), Anderson \& Nagaraja (1988), Chirase et al. (1988), Johnson et al. (1988), Reffet-Stabel et al. (1989) e Weiss \& Amiet (1990) registraram alterações provocadas pela lasalocida, principalmente diminuição na proporção molar de acetato e aumento na de propionato, sendo esses valores, significativos, ou não, conforme o período de tempo, após o inicio da aplicação do ionóforo.

Trabalhos de pesquisa mostraram que a adição

\footnotetext{
${ }^{1}$ Médico Veterinário - Mestre.

${ }^{2}$ Professor Titular USP, atualmente da UNISA. Endereço: Av.Dr.Cândido Mota Filho, 521/54 - Ed.San Rafael - CEP:05351-000 - São Paulo, SP. E.mail: cslucci@uol.com.br.

${ }^{3}$ Professor Assistente Doutor, Faculdade de Medicina Veterinária e Zootecnia/USP.
} 
de lasalocida aumenta o propionato no rúmen e, consequentemente, reduz a proporção acetato: propionato (Fuller \& Johnson, 1981; Ricke et al., 1984; Spears \& Harvey, 1987; Chirase et al. (1988). Rodrigues (1996), utilizando lasalocida em dietas com proporções volumoso/concentrado diferentes (70:30 e 40:60), relatou que os maiores efeitos do ionóforo, sobre aumento da proporção molar de propionato, ocorreram quando os animais receberam quantidades grandes de concentrados. Jacques et al. (1987) e Morris et al. (1990), ao administrarem lasalocida para novilhos, não observaram efeitos significativos sobre a proporção molar de ácidos graxos voláteis (AGV), sendo a proporção: volumoso/ concentrado semelhante. Knowlton et al. (1996a) e Knowlton et al. (1996b), trabalhando com vacas leiteiras em início de lactação, não demonstraram efeitos da lasalocida, sobre a quantidade de AGV totais.

Vários experimentos não têm registrado efeitos dos ionóforos sobre o pH ruminal, independentemente da relação volumoso/concentrado da dieta: Darden et al. (1985), Jacques et al. (1987), Morris et al. (1990), Bogaert et al. (1991), Clary et al. (1993), Knowlton et al. (1996b), Rodrigues (1996), Wessels et al. (1996) e Castro (1998). Entretanto, aumento no $\mathrm{pH}$ ruminal por ação da lasalocida também foi registrado por Anderson \& Nagaraja (1988), em ensaios in vivo. Finalmente, resultados demonstrando diminuição no $\mathrm{pH}$ ruminal, foram relatados por Beacom et al. (1988).

Em ensaios in vitro, quando o inóculo era obtido de animais adaptados aos ionóforos, nenhum efeito foi observado sobre o $\mathrm{pH}$ do conteúdo ruminal, mas quando era obtido de animais que receberam lasalocida um dia antes da coleta, o $\mathrm{pH}$ aumentou (Katz et al., 1986). Anderson \& Nagaraja (1988) relataram que a lasalocida não provocou alteração na concentração de amônia ruminal.

Ricke et al. (1984), ao alimentarem ovinos com ração contendo $66,7 \%$ de volumosos adicionada de lasalocida, observaram que o ionóforo tendeu a diminuir a taxa de passagem de sólidos e de líquidos, sem, contudo, causar alterações sobre volume líquido ruminal. Bogaert et al. (1991), Gomez et al. (1991), Galloway et al. (1993), Rodrigues (1996) e Wessels et al. (1996) não demonstraram efeitos da lasalocida sobre a taxa de passagem de sólidos e sobre o enchimento ruminal. Contrariamente, Jacques et al. (1987) demonstraram que o ionóforo administrado a novilhos sob pastejo determinou tendência em au- mentar o fluxo de líquidos e o volume líquido ruminal, mas não alterou a taxa de passagem de sólidos.

Diante dessa grande variabilidade dos resultados experimentais, e considerando a relevância dos ionóforos para a exploração animal, o presente trabalho teve, como objetivo, pesquisar os efeitos de doses e tempos de adaptação à lasalocida sódica, sobre parâmetros da fermentação ruminal, em bovinos.

\section{Material e Métodos}

O experimento foi realizado na Faculdade de Medicina Veterinária e Zootecnia da Universidade de São Paulo, "campus" de Pirassununga, utilizando-se quatro vacas mestiças Holandês-Zebu, confinadas, pesando em média $480 \mathrm{~kg}$, ao início do trabalho, portadoras de cânula ruminal. O delineamento experimental foi o quadrado latino 4 x 4 (Pimentel Gomes, 1985) com zero (0), 1, 2 e 3 semanas de adaptação para os seguintes tratamentos: controle, sem adição de lasalocida à dieta; $50 \mathrm{mg}$ de lasalocida/animal/ dia; $100 \mathrm{mg}$ de lasalocida/animal/dia; $200 \mathrm{mg}$ de lasalocida/animal/dia.

A fonte de lasalocida empregada foi administrada, diariamente, por intermédio da cânula ruminal. A dieta foi balanceada de forma a ser isonitrogenada, apresentando relação volumoso/concentrado de 1:1. A mistura de concentrados constituiu-se de farelo de soja e de grãos de milho moído, enquanto o único volumoso usado foi feno de coastcross (Cynodon dactylon). A dieta era fornecida em duas refeições, às 7 horas e 15 horas, em um sistema de mistura completa (concentrado + volumoso). A quantidade de ração foi fornecida de tal forma a não serem observadas sobras de alimento.

A composição bromatológica do feno e da mistura concentrada, separadamente, está descrita na Tabela 1 (AOAC, 1980). Foram coletadas amostras do feno e mistura concentrada a cada semana, durante todo o experimento, realizado em quatro subperíodos de seis semanas cada, sendo as quatro primeiras utilizadas para coleta de dados e as duas finais para eliminação de efeitos residuais. As variáveis analisadas foram: dosagem de níveis de amônia, de ácidos graxos voláteis acético, propiônico e butírico e do $\mathrm{pH}$ no conteúdo ruminal; estimativa de taxa de passagem e volume líquido ruminal.

As amostras de conteúdo do rumen foram obtidas de três pontos diferentes, correspondentes ao antro e saco ventrais anterior e posterior, através de bomba

R. Bras. Zootec., v.31, n.6, p.2299-2306, 2002 
Tabela 1 - Composição porcentual e bromatológica dos alimentos da ração, com base na matéria seca

Table 1 - Proportion and chemical composition of ration feeds, as dry matter basis

\begin{tabular}{|c|c|c|c|}
\hline \multicolumn{2}{|l|}{$\begin{array}{l}\text { Ingredientes } \\
\text { Ingredient }\end{array}$} & \multicolumn{2}{|c|}{ Quantidade (\%) } \\
\hline \multicolumn{2}{|c|}{ Feno de coastcross } & \multicolumn{2}{|l|}{50,0} \\
\hline \multicolumn{4}{|c|}{ Coastcross hay } \\
\hline \multicolumn{2}{|c|}{ Grãos de milho moído } & \multicolumn{2}{|l|}{41,0} \\
\hline \multicolumn{4}{|c|}{ Corn dent, ground } \\
\hline \multicolumn{2}{|c|}{ Farelo de soja } & \multicolumn{2}{|l|}{8,5} \\
\hline \multicolumn{4}{|c|}{ Soybean meal } \\
\hline Mistura mine & & 0,5 & \\
\hline & & & \\
\hline Composição & Feno & Concentrados & Ração \\
\hline Composition & Hay & Concentrates & Ration \\
\hline $\mathrm{MS}(\%)$ & 87,28 & 86,44 & 86,86 \\
\hline $\mathrm{PB}(\%)$ & 9,49 & 17,08 & 13,29 \\
\hline $\mathrm{FB}(\%)$ & 36,37 & 2,80 & 19,59 \\
\hline FDA $(\%)$ & 50,89 & 7,32 & 29,11 \\
\hline FDN $(\%)$ & 82,63 & 21,51 & 52,07 \\
\hline $\mathrm{EE}(\%)$ & 1,00 & 3,38 & 2,19 \\
\hline MM (\%) & 6,74 & 2,87 & 4,81 \\
\hline$* \operatorname{NDT}(\%)$ & 50,00 & 89,00 & 69,5 \\
\hline $\mathrm{Ca}(\%)$ & 0,39 & 0,39 & 0,39 \\
\hline $\mathrm{P}(\%)$ & 0,17 & 0,36 & 0,27 \\
\hline
\end{tabular}

de vácuo. Durante as coletas foram retirados cerca de $500 \mathrm{~mL}$ de conteúdo ruminal, devolvendo-se ao proventrículo a quantidade não utilizada para as alíquotas destinadas às diferentes análises. Com exceção das amostras referentes à mensuração do volume e taxa de passagem de líquidos, todas as demais foram realizadas às $0,2,4,6$ e $8 \mathrm{~h}$ após o arraçoamento matinal, efetuado às $7 \mathrm{~h}$. A segunda refeição foi oferecida somente às $15 \mathrm{~h}$, quando encerrada a última amostragem. A amostra de $0 \mathrm{~h}$ foi colhida, imediatamente, antes da primeira refeição.

A determinação dos AGV contidos no líquido ruminal foi realizada através de cromatografia gasosa, segundo método preconizado por Erwin et al. (1961). Foram empregados $100 \mathrm{~mL}$ de líquido ruminal, quantidade que foi centrifugada, tomando-se $1 \mathrm{~mL}$ do sobrenadante em um tubo de ensaio, arrolhado, ao qual foi adicionado $0,2 \mathrm{~mL}$ de ácido formico. $\mathrm{O}$ material foi conservado em congelador a $-20^{\circ} \mathrm{C}$, até o momento da análise. Para a análise foi empregado cromatógrafo a gás, sendo o nitrogênio usado como gás de arraste; o oxigênio, como gás comburante; e o hidrogênio, como combustível. Foram feitas repetições necessárias para que a diferença entre leituras fosse inferior a $5 \%$.

Para determinação do $\mathrm{pH}$, imediatamente, após a coleta, $100 \mathrm{~mL}$ de fluido ruminal foram utilizados em potenciômetro digital portátil calibrado com soluções tampão de pH 4,0 e 7,0.

A determinação do nitrogênio amoniacal $\left(\mathrm{N}_{-} \mathrm{NH}_{3}\right)$ foi realizada por colorimetria, segundo método proposto por Kulasek (1972) e adaptado por Foldager (1977). Para determinação do N amoniacal, alíquotas de $2 \mathrm{~mL}$ de líquido ruminal foram colocadas em tubos de ensaio contendo $1 \mathrm{~mL}$ de solução de ácido sulfurico $1 \mathrm{~N}$, os quais permaneceram armazenados em refrigerador até realização da análise. Nesta oportunidade foi executada desproteinização adicionando-se $1 \mathrm{~mL}$ de tungstato de sódio, $10 \%$ à amostra, e posteriormente levando-se à centrifugação. Do sobrenadante, foram pipetados 25 microlitros, levados a um tubo de ensaio, acrescentando-se $5 \mathrm{~mL}$ de reagente fenol e $5 \mathrm{~mL}$ de reagente hipoclorito. Os tubos, uma vez fechados, foram conduzidos a banhomaria a $37^{\circ} \mathrm{C}$, por 15 minutos. Leituras de absorbância das amostras permitiram calcular as concentrações de $\mathrm{N}-\mathrm{NH}_{3}$, através de regressão linear obtida a partir de calibração do aparelho espectofotometro com soluções padrão de diferentes concentrações, admitindo-se $\mathrm{R}^{2}$ mínimo de 0,99 para a curva.

A determinação do volume líquido e da taxa de passagem de líquidos pelo rúmen foi realizada através do Polietilenoglicol (PEG) de peso molecular 4.000 , introduzindo-se $300 \mathrm{~g}$ deste indicador no rúmen, através de cânula ruminal, no $7^{\circ}, 14^{\circ}, 21^{\circ}$ e $28^{\circ}$ dia de cada subperíodo, segundo o método preconizado por Hyden (1956). Colocado o indicador (zero hora), foram colhidas amostras do líquido ruminal às $1,2,4 \mathrm{~h}$, $6,8,12$ e 24 horas após sua aplicação. Do líquido ruminal, centrifugado no local da coleta, colheu-se sobrenadante que ficou armazenado sob refrigeração até execução da análise. Esta principiou pela desproteinização da amostra, na qual, em seguida, provocou-se turvação do PEG adicionando-se ácido tricloroacético $30 \%$, em diferentes diluições da amostra com água destilada. Após 5 minutos de espera, procedeu-se à leitura da absorbância em espectofotômetro. Foi feita uma curva de controle com solução padrão, admitindo-se $\mathrm{R}^{2}$ mínimo de 0,99 . A taxa de passagem de líquidos, em porcentagem por hora, foi calculada através do emprego de regressão linear do logaritmo 
natural da concentração do PEG em função do tempo. O volume líquido ruminal foi obtido extrapolando-se a concentração inicial (zero hora) e considerando-se a dosagem do indicador, $300 \mathrm{~g}$ por animal.

Os resultados foram analisados por intermédio do programa computacional Statistical Analysis System (SAS, 1985). Os dados foram submetidos à análise de regressão do tipo polinomial para o efeito de dosagem de lasalocida, considerando-se os intervalos desproporcionais de dosagens. Foi calculado o fator medidas no tempo, referentes a cada uma das quatro semanas de colheita de dados. Quando as interações entre tempo e tratamento foram significativas, análises dos efeitos foram realizadas tanto dentro dos tempos, como dentro dos níveis de lasalocida. Adotou-se um nível de significância de 5\% para todos os testes realizados.

\section{Resultados e Discussão}

Os valores dos AGV totais, obtidos pela soma dos ácidos acético, propiônico e butírico encontram-se na Tabela 2. Não foram observados efeitos de níveis crescentes de lasalocida sódica sobre os teores de AGV totais $(\mathrm{P}=0,9459)$. Estes resultados concordam com os apresentados por Funk et al. (1986), Jacques et al (1987) e Rodrigues (1996). Entretanto, discordam dos registrados por Dye et al. (1988) os quais mostram diminuição na concentração total de AGV ao empregarem o ionóforo na alimentação de bovinos que recebiam volumoso de baixa qualidade. Ainda sobre a concentração total dos $\mathrm{AGV}$, não foram observados efeitos de tempo $(\mathrm{P}=0,9108)$ e interação tempo $\mathrm{x}$ tratamento $(\mathrm{P}=0,9105)$ : os níveis de $\mathrm{AGV}$ totais não foram significativamente diferentes ao longo das quatro semanas de cada subperíodo. De acordo com estes resultados, o período de adaptação (tempo decorrido desde o início de fornecimento de lasalocida) não apresentou efeito sobre a concentração total de AGV. Spears \& Harvey (1987) também não encontraram efeito da lasalocida sobre a concentração total de AGV, após 28 dias do início do experimento. Contrariamente, Weiss \& Amiet (1980) observaram efeito do ionóforo aos sete dias de aplicação, mas não mais aos 28 ou aos 98 dias após o início do experimento, sugerindo assim um possível efeito de adaptação da flora bacteriana ruminal à lasalocida, com o passar do tempo.

Os teores de ácido acético no rúmen não foram alterados de forma significativa pelos tratamentos. Os valores encontrados foram iguais a $70,44 \mathrm{mM}$ para o controle, 70,62 mM para o nível $50 \mathrm{mg}, 70,04 \mathrm{mM}$ para o nível $100 \mathrm{mg}$ e $69,54 \mathrm{mM}$ para o nível de $200 \mathrm{mg}$ / animal/dia, com a média geral de 70,16 mM. Não foram encontrados efeitos de tempo e diferentes níveis de lasalocida $(\mathrm{P}=0,1395)$ sobre a concentração de ácido acético, o qual apresentou uma média de 69,73 mMna semana 1, seguido de 70,43 mM na semana 2, 70,15 $\mathrm{mM}$ na semana 3 e 70,33 $\mathrm{mM}$ na semana 4 .

Quanto à concentração de propionato, observa-se na Tabela 3 não houve efeitos de tempo $(\mathrm{P}=0,3521)$ ou de tratamentos $(\mathrm{P}=0,1146)$ sobre os valores totais deste ácido.

Apresentando o mesmo comportamento dos outros dois ácidos, a concentração de butirato também não foi afetada significativamente pelo efeito de tempo $(\mathrm{P}=0,7373)$ e pelos diferentes níveis de lasalocida utilizados $(\mathrm{P}=0,3919)$. As médias das concentrações de butirato foram: 10,68; 10,12;10,46; e 10,23 mM, respectivamente, para o controle e os níveis de lasalocida 50, 100 e $200 \mathrm{mg} / \mathrm{animal} / \mathrm{dia}$. Quanto aos períodos de adaptação, os valores encontrados foram: na semana 1 de 10,55 $\mathrm{mM}$; na semana 2,10,18 mM; na semana 3, 10,46 mM; e na semana 4, 10,30 mM.

Tabela 2 - Efeitos de níveis crescentes de lasalocida sódica (mg/animal/dia) sobre os teores das somas dos ácidos graxos voláteis acético, propionico e butírico, em diferentes semanas de coleta

Table 2 - Effects of sodic lasolocid crescent levels (mg/ animal/day) on the total volatile fatty acids acetis, propionic and butiric, in different weeks of collection

\begin{tabular}{|c|c|c|c|c|c|c|}
\hline \multirow[t]{2}{*}{$\begin{array}{l}\text { Semana } \\
\text { Week }\end{array}$} & \multicolumn{4}{|c|}{$\begin{array}{c}\text { Tratamentos } \\
\text { Factors }\end{array}$} & \multirow[t]{2}{*}{$\begin{array}{l}\text { Média } \\
\text { Mean }\end{array}$} & \multirow[t]{2}{*}{$\mathrm{CV}(\%)$} \\
\hline & 0 & 50 & 100 & 200 & & \\
\hline \multicolumn{7}{|c|}{$\begin{array}{l}\text { mg/animal/dia } \\
\text { mg/animal/day }\end{array}$} \\
\hline 1 & 66,25 & 68,59 & 74,00 & 69,17 & 69,51 & 14,03 \\
\hline 2 & 68,89 & 67,80 & 72,44 & 67,78 & 69,23 & 15,69 \\
\hline 3 & 65,72 & 67,08 & 75,18 & 64,87 & 68,21 & 15,28 \\
\hline 4 & 69,19 & 69,01 & 71,84 & 65,75 & 68,94 & 15,28 \\
\hline $\begin{array}{l}\text { Média } \\
\text { Mean }\end{array}$ & 67,51 & 68,12 & 73,36 & 66,89 & 68,97 & 14,73 \\
\hline
\end{tabular}

Probabilidade:Linear =0,9459; Quadrática $=0,0616 ;$ Desvios $=0,1609$. Probability: Linear $=0.9459 ;$ Quadratic $=0.0616$; Error $=0.1609$.

Efeito de tempo $=\mathrm{P}=0,9108$.

Time effect: 0.9108 .

Interação tempo $x$ linear $=P=0,7543$.

Time $x$ linear interaction $=P=0.7543$.

Interação tempo $x$ quadrático $=\mathrm{P}=0,6786$.

Time $x$ quadratic interaction $=P=0.6786$.

Interação tempo $x$ desvio $=P=0,4724$.

Time $x$ error interception $=P=0.4724$.

R. Bras. Zootec., v.31, n.6, p.2299-2306, 2002 
Os resultados concernentes aos AGV foram semelhantes aos relatados por Thoney et al. (1981), Rodrigues (1986), Knowlton et al.(1996a), Knowlton et al. (1996b) e Wessels et al. (1996), que também não constataram efeitos significativos da aplicação de diferentes níveis de lasalocida sobre a concentração dos ácidos acético, propiônico e butírico. Entretanto, discordam de pesquisadores que registraram influência significativa do ionóforo sobre as concentrações de AGV, quando, de modo geral, os resultados foram caracterizados por aumento do propionato em detrimento do acetato e/ou butirato: McCartor et al. (1979), Fuller \& Johnson (1981), Paterson et al. (1983), Funk et al.(1986), Beacom et al. (1988), Bogaert et al. (1991), Galloway et al. (1993) e Block \& Burchard (1998).

Não ocorreram diferenças significativas entre níveis de lasalocida e períodos de adaptação, ao longo das quatro semanas de cada subperíodo, com respeito à produção dos ácidos acético, propiônico e butírico. Contudo, estes resultados não coincidem com os apresentados por Johnson et al. (1988), Reffet-Stabel et al. (1989) e Weiss \& Amiet (1990), que registraram efeitos de períodos de adaptação ao ionóforo sobre as concentrações de AGV no conteúdo do rumen.

Weiss \& Amiet (1990) observaram que a lasalocida aumentou a proporção molar de propionato e diminuiu a concentração de butirato, após 28 dias do fornecimento do ionóforo, registrando ainda incremento na proporção molar de propionato e redução na de acetato no sétimo dia após o início da administração da lasalocida.

Com respeito à proporção acetato/propionato, não foram observados efeitos de tratamento $(\mathrm{P}=0,0993)$, caracterizados pela administração de 0 , 50,100 e $200 \mathrm{mg} / \mathrm{animal} / \mathrm{dia}$, da mesma forma que não foram constatados efeitos de tempo $(\mathrm{P}=0,7527)$. Os valores da relação acetato:propionato compreenderam medias de 3,$74 ; 3,71 ; 3,68$; e 3,47 , respectivamente, para o controle e os níveis $50,100 \mathrm{mg}$. e 200 $\mathrm{mg} / \mathrm{animal} / \mathrm{dia}$, com média geral de 3,65. Quanto às relações para os diferentes períodos, na semana 1 foi de 3,59, acompanhada de 3,68 na semana $2 ; 3,67$ na semana 3 e 3,67 na semana 4, em concordância com dados apresentados por Thoney et al. (1981), Knowlton et al. (1996a), Knowlton et al. (1996b) e Wessels et al. (1996).

Em contrapartida, outros autores registraram efeitos sobre a relação acetato: propionato após o fornecimento dos ionóforos (Paterson et al., 1983; Beacom et
Tabela 3 - Efeitos de níveis crescentes de lasalocida sódica (mg/animal/dia) sobre os níveis de ácido propiônico em diferentes semanas de coleta

Table 3 - Effects of sodic lasaloid crescent levels (mg/animal/day) on the propionic and concentration in different weeks of collections

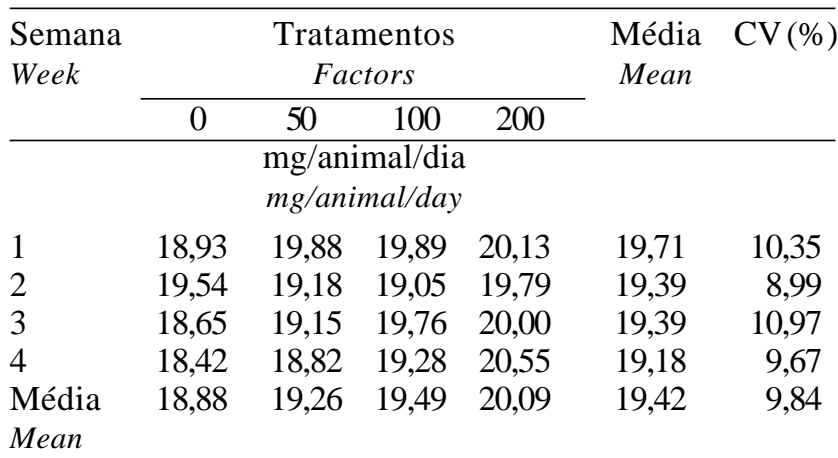

Probabilidade $=$ Linear $\mathrm{P}=0,1146 ;$ Quadrática $=\mathrm{P}=0,9067$ Desvios $=\mathrm{P}=0,8795$.

Probability: Linear $=0.1146 ;$ Quadratic $=0.9067 ;$ Error $=0.8795$

Efeito de tempo $=\mathrm{P}=0,3521$.

Time effect: 0.3521 .

Interação tempo $x$ linear $=\mathrm{P}=0,1820$

Time $x$ linear interaction $=P=0.1820$.

Interação tempo $x$ quadrática $=P=0,8546$.

Time $x$ quadratic interaction $=P=0.8546$.

Interação tempo $x$ desvio $=P=0,2106$.

Time $x$ error interception $=P=0.2106$.

al., 1988; Johnson et al., 1988; Weiss \& Amiet, 1990; Bogaert et al., 1991; e Block \& Burchard, 1998).

Weiss \& Amiet (1990) registraram que a proporção acetato/propionato foi $18,9 \%$ inferior no sétimo em relação ao primeiro dia de administração da lasalocida. Na presente pesquisa, os valores de 50, 100 e $200 \mathrm{mg}$ de lasalocida provocaram, contrariamente, aumento da proporção acetato/propionato, da primeira para a segunda semana experimental, de respectivamente 4,2; 8,1; e 1,4\%. Johnson et al (1988) registraram queda de $17,8 \%$ da proporção acetato/ propionato aos 35 dias após o início da administração de lasalocida, mas essa diferença desapareceu aos 70 dias de administração. Nesta pesquisa, aos 28 dias do início do experimento, somente o nível de $200 \mathrm{mg}$ de lasalocida /dia causou diminuição da relação acetato/ propionato, embora não significativa, da ordem de $8,2 \%$ em relação ao tratamento controle.

As concentrações de nitrogênio amoniacal foram 10,$16 ; 11,44 ; 11,07 ;$ e $11,66 \mathrm{mg} / \mathrm{dL}$, respectivamente, para o tratamento controle e níveis de 50, 100 e 200 $\mathrm{mg}$ de lasalocida /animal/dia. Estes resultados determinaram um valor médio de $11,08 \mathrm{mg} / \mathrm{dL}$ para a concentração de nitrogênio da amônia no conteúdo ruminal, o qual, segundo a classificação de Mehres et al (1977), se encontra dentro do limite recomendado, 
abaixo de $24 \mathrm{mg} / \mathrm{dL}$. Entretanto, outros autores registraram diferentes parâmetros para os níveis de nitrogênio de amônia no líquido do rúmen necessários ao máximo crescimento microbiano, destacando-se Satteer \& Slyter (1974) e Preston \& Leng (1987), descrevendo limites de 5,0 a 9,6 mg/dL.

Não houve efeito de tratamentos sobre a concentração de nitrogênio amoniacal do conteúdo do rumen $(\mathrm{p}=0,1688)$. Resultados semelhantes foram registrados por Rodrigues (1986), Dye et al (1988), Reffett-Stabel et al (1989) e Morris et al (1990). As diminuições das concentrações ruminais de nitrogênio de amônia com o uso de ionóforos poderia ocorrer por ser inibida a deaminação e proteólise ruminal, aumentando o escape da proteína da dieta (Poos et al., 1999) ou ainda, devido ao aumento do crescimento microbiano (Chalupa, 1977).

O efeito da interação tempo x níveis de amônia no rúmen não foi significativo ( $\mathrm{p}=0,9763)$ neste experimento. Os valores registrados foram 11,08 mg/dL, na semana $1,11,26 \mathrm{mg} / \mathrm{dL}$ na semana $2 ; 10,92 \mathrm{mg} / \mathrm{dL}$ na semana 3 e $11,08 \mathrm{mg} / \mathrm{dL}$ na semana 4 . A média geral foi de $11,08 \mathrm{mg} / \mathrm{dL}$, considerando todo o período diário de amostragem, desde momentos antes da refeição até 8 horas após.

A taxa de passagem de líquidos não foi afetada significativamente pelos tratamentos $(p=0,4045)$ ou pelos períodos de adaptação $(p=0,5489)$ e interação períodos $\mathrm{x}$ tratamentos $(\mathrm{p}=0,3925)$. As médias das taxas de passagem foram $10,35 \%$ /hora na semana 1 , $10,21 \%$ /hora na semana $2,10,05 \%$ /hora na semana 3 e $10,00 \% /$ hora na semana 4 . As médias por tratamento foram $10,11 \% / \mathrm{h} ; 10,00 \% / \mathrm{h}, 10,35 \% / \mathrm{h} \mathrm{e} 9,23 \%$, respectivamente, para controle, 50, 100 e $200 \mathrm{mg}$ de lasalocida/animal/dia. A média geral das taxas de passagem foi de 10,15\%/hora. Estes dados foram semelhantes aos obtidos por Gomez et al. (1991), Clary et al. (1993), Rodrigues (1996), Wessels et al. (1996) e Knowlton et al. (1996b). Entretanto, resultados contrários foram observados por Jacques et al (1987), que mostraram aumento de $52,7 \%$ na taxa de passagem de líquidos após ofornecimento de lasalocida.

A taxa de passagem de líquidos foi bastante próxima aos 9,8\%/h e 10,8\%/h obtidos por Rodrigues (1996) e Castro (1998), respectivamente, ficando um pouco acima dos $8,0 \% / h$ encontrados por Jacques et al. (1987) e muito superior a $6,5 \% / \mathrm{h}$ obtido por Clary et al. (1993).
O volume de líquido no rúmen apresentou média de 45,51 litros, na semana 1, seguida de 45,43 litros na semana 2, 46,83 litros na 3 e 46,46 litros na 4 . Em termos de tratamentos, as médias foram: 46,75 litros, 44,77 litros, 46,69 litros e 45,89 litros, respectivamente, para os grupos controle, 50,100 e $200 \mathrm{mg}$ de lasalocida/animal/dia. A média geral do volume do rúmen foi igual a 46,07 litros. Os valores são muito próximos aos encontrados por Clary et al (1993) de 46,6 litros para novilhas com $430 \mathrm{~kg}$ de peso, mas um pouco mais baixos que os encontrados por Jacques et al (1987) de 56,7 litros para novilhos de $227 \mathrm{~kg}$ de peso.

Não foi observado efeito de tratamento $(\mathrm{p}=0,9271)$, de períodos de adaptação $(\mathrm{p}=0,7317)$ e da interação períodos $\mathrm{x}$ tratamentos $(\mathrm{p}=0,9304)$ sobre o volume líquido do rúmen, concordando com resultados obtidos por Ricke et al. (1984) e Clary et al. (1993). Discordam, no entanto, dos obtidos por Gomez et al. (1991) e Wessels et al. (1996), que registraram diminuição do volume líquido ruminal com o emprego do ionóforo.

Os valores médios de $\mathrm{pH}$ ruminal foram estatisticamente semelhantes $(\mathrm{p}=0,0941)$, iguais a 6,$40 ; 6,55$; 6,48 ; e 6,39, respectivamente, para os tratamentos controle, 50, 100 e $200 \mathrm{mg}$ de lasalocida/animal/dia. Estes resultados corroboram os registrados por Darden et al (1985), Morris et al (1990), Bogaert et al. (1991), Clary et al. (1993), Knowlton et al. (1996b), Rodrigues (1996), Wessels et al. ( 1996) e Castro (1998) e, ao menos na situação do presente experimento, não confirmam a descrição de Chalupa (1977) de que a lasalocida poder alterar o $\mathrm{pH}$ ruminal.

\section{Conclusões}

Nas condições sob as quais foi desenvolvido o presente experimento, os resultados não permitem indicar a aplicação de lasalocida sodica para bovinos, na expectativa de provocar alterações significativas na fermentação ruminal, a saber, nas concentrações de ácidos graxos voláteis, de amônia, e valores de $\mathrm{pH}$ do conteúdo do rúmen. Períodos de adaptação de zero a três semanas em nada modificaram os resultados. A lasalocida também foi inoperante nos valores de volume líquido ruminal e taxa de passagem de líquidos pelo rúmen. 


\section{Literatura Citada}

ANDERSON, K.L.; NAGARAJA, T.G. Performance and ruminal changes of early weaned calves fed lasalocid. Journal of Animal Science, v.66, p.806-813, 1988.

ASSOCIATION OF OFFICIAL ANALYTICAL CHEMISTIS - AOAC. Official methods of analysis. 11.ed. Washington, D.C.: AOAC, 1980. 1051p.

BEACOM, S.E.; MIR, Z.; KORSRUD, G.O. et al Effect of the feed additives chlortetracycline, monensin and lasalocid on feedlot performance of finishing cattle, liver lesions and tissue levels of chlortetracycline. Canadian Journal of Animal Science, v.68, n.4, p.1131-41, 1988.

BLOCK, E.; BURCHARD, J.F. Use of ionophores in dairy production. $n^{\circ}$. Proceeding of eastern nutrition conference, Quebec, p.81-88, 1998

BOGAËRT, C.; GOMEZ, L.; JOUANY, J.P. Effects of lasalocid and cationomycin on the digestion of plant cell walls in sheep. Canadian Journal of Animal Science, v.71, p.379, 1991

CASTRO, A.L. Efeito da lasalocida sódica sobre a digestibilidade de dietas contendo cana de açúcar (Saccarum ossicinarum), em bovinos contendo fístula ruminal. São Paulo: Universidade de São Paulo, 1998. 95p. Dissertação (Mestrado) - Universidade de São Paulo, 1998.

CHALUPA, W. Manipulating rumem fermentation. Journal of Animal Science, v.45, p.585, 1977.

CHEN, M.; WOLIN, M.F. Effect of monensin and lasalocid sodium on the growth of methanogenic and saccharolytic bacteria. Applied Environmental Microbiology, v.38, p.72, 1979.

CHIRASE, N.K.; GREENE, L.W.; LUNT, D.K. et al. Serum and ruminal fluid characteristics of beef cows grazing oat pastures and supplemented with or without lasalocid. Journal of Animal Science, v.66 n.7 p.1746-1754, 1988.

CLARY, E.M.; BRANDT, R.T.; HARMON, D.L. et al. Supplemental fat and ionophores in finishing diets: feedlot performance and ruminal digest kinetics in steers. Journal of Animal Science, v.71,n.11, p.3115-23, 1993

DARDEN, D.E.; MERCHEN, N.R.; BERGER, L.L. et al. Effects of avoparcin, lasalocid, and monensin on sites of nutrient digestion in beef steers. Nutrition Report International, v.31, n.4, p.979-89, 1985.

DYE, B.E.; AMOS, H.E.; FROETSCHEL, M.A. Influence of lasalocid on rumen metabolites, milk production, milk composition and digestibility in lactating cows. Nutrition Report International, v.38, n.1, p.101-15, 1988.

ERWIN, W.S.; MARCO, G.J., MERY, E.M. Volatile fat acid analyses of blood a rumen fluid by gas chromatography. Journal of Dairy Science, v.44, p.1768-71, 1961.

FOLDAGER, J. Protein requirement and non protein nitrogen for high producing cow in early lactation. $\mathrm{PhD}$ Thesis East Lansing - Michigan State University, 1977.

FULLER, J.R.; JOHNSON, D.E. Monensin and lasalocid effects on fermentation in vitro. Journal of Animal Science, v.56, p.1574-1580, 1981.

FUNK, M.A.; GALYEAN, M.L.; ROSS, T.T. Potassium and lasalocid effects on performance and digestion in lambs. Journal of Animal Science, v.63, n.3, p.685-91, 1986.

GALLOWAY Sr., D.L.; GOETSCH, A.L.; PATIL, A. et al. Feed intake and digestion by Holstein steer calves consuming low-quality grass supplemented with lasalocid or monensina. Canadian Journal of Animal Science, v.73, n.4, p.869-79, 1993.

R. Bras. Zootec., v.31, n.6, p.2299-2306, 2002
GOMEZ, L.; BOGAËRT, C.; JOUANY, J.P. et al. The influence of lasalocid and cationomycin on nitrogen digestion in sheep: comparison of methods for estimating microbial nitrogen. Canadian Journal of Animal Science, v.71, n.2, p.389-399, 1991.

HYDEN, S.A Turbidometric method for the determination of higher polyethylene glycols in biological materials. Kungliga Lantbrukshogskolans Annaler, v.22, p.139-145, 1956.

JACQUES, K.A.; COCHRAN, R.C.; CORRAH, L.R. et al. Influence of lasalocid level on forage intake, digestibility, ruminal fermentation liquid flow and performance of beef cattle grazing winter range. Journal of Animal Science, v.65, n.3, p.777-85, 1987.

JOHNSON Jr., J.C.; UTLEY, P.R.; MULLINIX Jr., B.G. et al. Effects of adding fat and lasalocid to diets of dairy cows. Journal of Dairy Science, v.71, n.8, p.2151-2165, 1988

KATZ, M.P.; NAGARAJA, T.G.; FINA, L.R. Ruminal changes in monensin and lasalocid fed cattle grazing bloat provocative alfalfa pasture. Journal of Animal Science, v.73, n.4, p.1246-57, 1986.

KNOWLTON, K.F; ALLEN, M.S; ERICKSON, P.S. Lasalocid and particle size of corn grain for dairy cows in early lactation. 1. Effect on performance, serum metabolites, and nutrient digestibility. Journal of Dairy Science, v.79, p.557-564, 1996a.

KNOWLTON, K.F; ALLEN, M.S.; ERICKSON, P.S. Lasalocid and particle size of corn grain for dairy cows in early lactation. 2. Effect on ruminal measurements and feeding behaviour. Journal of Dairy Science, v.79, p.565-574, 1996b.

KULASEK, G.A. Micromethod for determination of urea in plasma, whole blood and blood cells using urease and phenol reagent. Polske Archiwum Weterynayjne, v.15, n.4, p.801-810, 1972.

McCARTOR, M.M.; RANDEL, R.D.; CARROLL, L.H. Dietary alteration of ruminal fermentation on efficiency of growth and onset of puberty in brangus heifers. Journal of Animal Science, v. 48, p.488-494, 1979.

MORRIS, F.E.; BRANINE, M.E.; GALUEN, M.L. et al. Effects of rotating monensin plus tylosin and lasalocid on performance, ruminal fermentation, and site and extent of digestion in feedlot cattle. Journal of Animal Science, v.68, n.10, p.3069-78, 1990.

NATIONAL RESEACH COUNCIL - NRC. Nutrient requirements of dairy cattle. Washington, D.C.: National Academy of Science, National Academy Press, 1989. 158p.

PATERSON, J.A.; ANDERSON, B.M.; BOWMAN, D.K. et al. Effect of protein source and lasalocid on nitrogen digestibility and growth by ruminants. Journal of Animal Science, v.57, n.6, p.1537-44, 1983.

POOS, M.I.; HANSON, T.L.; KLOPFENSTEIN, T.J. Monensin effects on diet digestibility, ruminal protein bypass and microbial protein synthesis. Journal of Animal Science, v.48, p.1516, 1979.

PRESTON, T.R.; LENG, R.A. Matching ruminant prodution systems with avaliable resourses in the tropics and subtropics. Armidale: Penambul Books, 1987. 245p.

REFFETT-STABEL, J.; SPEARS, J.W.; HARVEY, R.W. et al. Salinomycin and lasalocid effects on growth rate, mineral metabolism and ruminal fermentation in steers. Journal of Animal Science, v.67, n.10, p.2735-42, 1989.

RICKE, S.C.; BERGER, L.L.; Van Der AAR. et al. Effects of lasalocid and monensin on nutrient digestion, metabolism and rúmen characteristics of sheep. Journal of Animal Science, v.58, n.1, p.194-202, 1984. 
RODRIGUES, P.H.M. Efeito da lasalocida sódica e proporção de volumoso/concentrados sobre a fermentação ruminal e degradabilidade in situ do farelo de soja e do feno de coastcross (Cynodon dactylon). São Paulo, 1996. 135p Dissertação (Mestrado) - Faculdade de Medicina Veterinária e Zootecnia da Universidade de São Paulo, 1996.

SATTER, L.D.; SLYTER, L.L. Effect of ammonia concentration on rumen microbial protein production in vitro. British Journal of Nutrition, v.32, p.199-208, 1974

SPEARS, J.W. Ionophores and nutrient digestion and absorption in ruminants. Journal of Nutrition, v.120, p.632, 1990.

SPEARS, J.W.; HARVEY, R.W. Lasalocid and dietary sodium and potassium effects on mineral metabolism, ruminal volatile fatty acids and performance of finishing steers. Journal of Animal Science, v.65, n.3, p.830-40, 1987.
THONEY, M.L.; HEIDE, E.K.; DUHAIME, D.J. et al. Growth, feed efficiency and metabolite concentrations of cattle fed high forage diets with lasalocid or monensin supplements. Journal of Animal Science, v.52, p.427-433, 1981.

WEISS, W.P.; AMIET, B.A. Effect of lasalocid on performance of lactating cows. Journal of Dairy Science, v.73, n.1, p.153-162, 1990

WESSELS, R.H; TITGEMEYER, E.C; ARMENDARIZ, C.K. et al. Lasalocid effects on ruminal degradation of protein and postruminal supply of amino acids in Holstein steers. Journal of Dairy Science, v.79, p.1802-1808, 1996.

Recebido em: 15/05/01

Aceito em: 09/07/02 